Military Technical College Kobry Elkobbah, Cairo,

Egypt.

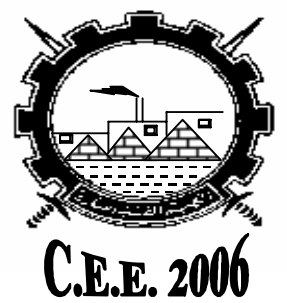

$3^{\text {rd }}$ International Conference

On

Chemical \& Environmental

Engineering

\title{
PREPARATION AND SENSITIVITY CHARACTERISTICS OF 3-NITRO- 1, 2, 4-TRIAZOL-5-ONE (NTO) -BASED CASTED EXPLOSIVE FORMULATIONS
}

\author{
Radwan M. A. ${ }^{\text {, }}$ Mostafa H. E. ${ }^{* *}$, Ahmed M. M. ${ }^{* *}$
}

\section{ABSTRACT}

Different explosive formulations based on 3-Nitro-1, 2, 4-triazol-5-one ( NTO), which is an extremely insensitive explosive, were prepared by casting with Trinitrotoluene (TNT) or Polyurethane (PU) to avoid casting problems originating from the high melting point of NTO. Synthesis of NTO was carried out by two consecutive reactions; condensation reaction of semicarbazide hydrochloride with formic acid to produce 1, 2, 4-triazol-5-one (TO), then nitration for the prepared (TO) with nitric acid. The obtained products from both reaction steps were characterized by the determination of melting point, infrared spectroscopy, and measurement of some explosive characteristics (Sensitivity to impact, friction, ignition temperature and delay of ignition). Different mixtures of NTO/TNT and NTO/PU were studied theoretically using a computer program. The obtained results of explosive performance parameters were utilized to select the explosive mixtures (NTO/TNT 65:35, NTO/PU 88:12) to be prepared and tested. Sensitivity to impact of TNT, prepared NTO and candidate formulations (NTO/PU 88:12, NTO/TNT 65:35) measured and compared together. Formulations based on NTO/PU have lowest sensitivity to impact (36 joule). The ignition temperatures of NTO/TNT $(65: 35)$ and for (NTO/PU) (88:12) explosive formulations were markedly less than that of pure TNT and pure NTO.

The obtained results of explosive performance parameters were used to determine the candidate explosive mixtures for future practical applications and work to explore the possible application of NTO in insensitive munitions (IM) compliant explosives.

\section{KEY WORDS}

NTO, TNT, PU, Sensitivity to impact, ignition temperature,

\footnotetext{
${ }^{*}$ British University in Egypt (BUE)

${ }^{* *}$ Egyptian Armed forces

${ }^{* * *}$ Karary Academy of Technology, Sudan Republic (M. Sc. Student MTC)
} 
ABBREVIATIONS

\begin{tabular}{|l|l|}
\hline BAMO & Poly(3,3-bis azido methyl oxetane) \\
\hline DOZ & Dioctyl azelate \\
\hline HMDI & Hexamethylene di-isocyanate \\
\hline HTPB & Hydroxy terminated polybutadiene \\
\hline MAPO & Methyl aziridinyl phosphine oxide \\
\hline NTO & 3-Nitro - 1,2,4- triazol- 5- one \\
\hline PBXs & Plastic bonded explosives \\
\hline PU & Polyurethane \\
\hline RDX & Cyclotrimethylenetrinitramine \\
\hline TATB & $1,3,5$ triamino 2,4,6 Trinitrobenzene \\
\hline TNT & $2,4,6$ Trinitrotoluene \\
\hline TO & $1,2,4-$-riazol-5-one \\
\hline
\end{tabular}

\section{INTRODUCTION}

Defense forces around the world are adopting Insensitive Munitions (IM), to minimize the response of ordnance items to accidental stimuli, thus increasing the survivability of personnel and scarce resources (both weapon systems and platforms) [1]. The application of IM can also have an important economic and logistic impact on stockpiling, storage and transport.

There are several approaches for the development of insensitive munitions, but prominent among them is the use of explosive fillings with reduced sensitivity, but in which performance is not compromised. Several important design considerations for such low sensitive explosive formulations include improvement of mechanical properties, reduced signature, extended service life and reduced environment impact during manufacture [2].

Insensitive munitions are those which reliably fulfill their performance, readiness and operational requirements on demand, but in which the violence of response to unplanned hazardous stimuli is restricted to an acceptable level .There are two general approaches to explosive formulations which satisfy IM requirements. The first is through the use of polymer bonded explosives (PBXs), in which the energetic sensitive component is dispersed in a rubbery matrix. The second is through the use of intrinsically insensitive energetic ingredients such as 1,3,5-triamino-2,4,6trinitrobenzene (TATB).

Many research where also focused on another possible intrinsically insensitive energetic material is 3-nitro-1, 2, 4-triazol-5- one (NTO) [3 - 7].

In this work different explosive formulations based on NTO, which is an extremely insensitive explosive were prepared by casting with Trinitrotoluene (TNT) or Polyurethane (PU) to avoid casting problems originating from the high melting point of NTO. 


\section{EXPERIMENTAL}

\subsection{Materials}

All the materials used in this work and their specifications are shown in table (1)

Table (1) Specifications of raw materials used in experimental work

\begin{tabular}{|c|c|c|c|c|}
\hline Material & $\begin{array}{c}\text { Purity } \\
(\%)\end{array}$ & $\begin{array}{c}\text { Density } \\
\left(\mathbf{g} / \mathbf{c m}^{\mathbf{3}}\right)\end{array}$ & $\begin{array}{c}\text { Boiling point } \\
\left({ }^{\mathbf{O}} \mathbf{C}\right)\end{array}$ & Source \\
\hline $\begin{array}{c}\text { Semicarbazide } \\
\text { hydrochloride }\end{array}$ & 98 & - & $173-178$ & SRL, India \\
\hline Formic acid & 85 & 1.20 & 101 & Riedel-dehaen \\
\hline Nitric acid & 98 & 1.50 & & AZC,Egypt \\
\hline HTPB & - & 0.90 & - & "Iverise co" Brazil \\
\hline DOZ & - & 0.91 & 376 & $\begin{array}{c}\text { Marano CO. Inc, } \\
\text { New York, USA }\end{array}$ \\
\hline HMDI & - & - & 255 & Aldrich, Germany \\
\hline MAPO & - & 1.1 & 159.5 & Arsyn co Inc,USA \\
\hline
\end{tabular}

\subsection{Preparation of NTO}

\subsubsection{Preparation of TO}

Formic acid was added proportionally to solid semicarbazide hydrochloride placed in three-necked round bottom nitrator. The mixture was magnetically stirred under reflux in temperature range $80-90{ }^{\circ} \mathrm{C}$ till dissolution of the entire solid semicarbazide hydrochloride. The excess formic acid was removed by normal distillation until the start of crystallization. Distilled water was added and distillation was continued till the start of the mixture dryness. Then mixture was cooled to room temperature overnight to be ready for nitration. Scheme 1 describes the chemical reaction equation of the formation of TO.<smiles></smiles>

Scheme (1) Synthesis of TO 


\subsubsection{Nitration of TO}

To a mechanically stirred nitrator, containing fuming nitric acid (98\%), (TO) product was carefully added on fractions over a period of 120 minutes at $25{ }^{\circ} \mathrm{C}$. The nitrated product was cooled down in a water bath then cold water was added to the nitrated mixture to precipitate NTO crystals. NTO crystals were purified by recrystallization from distilled water, filtered, washed with water and finally the product of NTO was dried at $60{ }^{\circ} \mathrm{C}$ for 24 hours. Scheme 2 describes the chemical reaction equation of the formation of NTO.

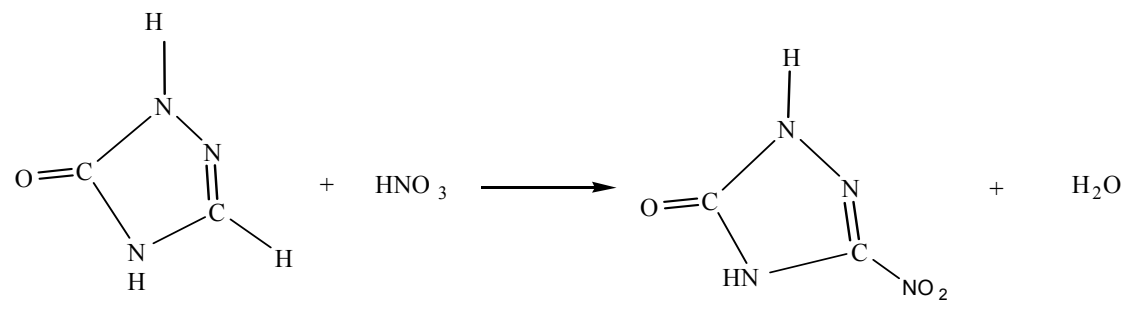

Scheme (2) Synthesis of NTO

\subsection{Preparation of NTO-based explosives formulation}

Based on the values of different explosive characteristics obtained by applying a novel computer program to calculate the explosive performance of different explosive formulations, the explosive mixtures (NTO/TNT 65:35, NTO/PU 88:12) were selected to be prepared experimentally and tested.

\subsubsection{Preparation of NTO/TNT formulation using melt-casting technique}

The calculated amount of TNT and NTO were accurately weighed. TNT was then placed into the glass flask $(300 \mathrm{ml})$ and heated to $90{ }^{\circ} \mathrm{C}$ on a water bath for approximately 30 minutes. After complete melting of TNT, NTO was added slowly on stirring which was continued for approximately 30 minutes after complete addition of NTO to improve the mixing process. The molten mixture was then casted into suitable confinements to measure different explosive characteristics.

\subsubsection{Preparation of NTO/PU PBXs using casting technique}

The calculated amounts of HTPB as prepolymer, NTO and DOZ as plasticizer were accurately weighed. HTPB was then placed in a mixing kettle and mixed with two thirds of DOZ weight. NTO was then added in small portions during mixing for $1 / 2$ hour. Thorough mixing was conducted for about 10 minutes after complete addition of NTO to ensure complete coating. The residual amount of DOZ, MAPO as bonding agent and $\mathrm{HMDI}$ as curing agent, calculated on basis of $\mathrm{NCO} / \mathrm{OH}=1.3$, were added to the mixture and mixing continued for about 15 minutes. The formed matrix (paste) was then pressed into the mold relevant to each test. The prepared compositions were cured for 7 days at $55-60^{\circ} \mathrm{C}$. 


\subsection{Characterization of the prepared products}

\subsubsection{Melting point}

Digital melting point apparatus, IA9000 - (UK), was used in measuring the melting point of TO and NTO.

\subsubsection{Infrared Spectroscopy}

Shimadzu 80000 series FTIR was used to identify the product through FTIR spectrum. The solid sample and $\mathrm{KBr}$ were ground, mix and press in the form of a disc having standard dimensions, The wave number range used was $500-4000 \mathrm{~cm}^{-1}$ which represents the appropriate range for most organic compounds. Using the FTIR spectrum it was possible to identify the different functional groups in the prepared samples.

\subsection{Sensitivity of different prepared explosive formulations}

\subsubsection{Determination of sensitivity to impact}

Sensitivity to impact test was carried out using IKA-MASCHINENBAU apparatus by applying the standard test conditions [8]. The experiment was conducted using a weight of $5 \mathrm{~kg}$ and by changing the drop height. Six consecutive trials were performed for each drop height. The minimum height at which $100 \%$ initiation occurred was determined (the upper sensitivity limit); thus the energy required to initiate the explosive could be estimated.

\subsubsection{Determination of sensitivity to friction}

Chilworth BAM friction test apparatus, (UK), was used to determine the sensitivity to friction by applying the standard test conditions [8]. Sensitivity to friction was determined by spreading about $0.01 \mathrm{~g}$ of the dry explosive on the surface of the porcelain plate in the form of a thin layer. Different loads were used to change the normal force between the porcelain pistil and the plate; force varied from nearly 5 to $360 \mathrm{~N}$. The sample initiation may be observed through sound, smoke appearance, or by the characteristic smell of the decomposition products. Six consecutive trials were performed for each load and lever position.

\subsubsection{Determination of sensitivity to heat}

\section{(1) Ignition temperature}

The ignition temperature was performed by using Chilworth deflagration test apparatus, made in UK, by employing the standard test conditions [8]. Three samples of $0.2 \mathrm{~g}$ each were dried up and ground to suitable particle size then inserted into 3 test tubes which were placed vertically into the heating block and the temperature was uniformly increased $\left(5^{\circ} \mathrm{C} / \mathrm{min}\right)$ until deflagration of the sample occurred. The 
ignition temperature was read digitally on the control unit and the average temperature for the three samples was calculated.

\section{(2) Ignition temperature at constant delay period of ignition (5 s)}

Delay period of ignition of an explosive at certain temperature was experimentally determined by placing an explosive sample of a fixed mass at that temperature which should be higher than the previously determined ignition temperature of the explosive. The test is done using the same apparatus as before. The temperature was adjusted and fixed until the ignition took place and delay time was recorded. The samples of $0.05 \mathrm{~g}$ each were inserted into three test tubes already heated in the aluminum block to the investigated temperature and stopwatch was used to measure the time elapsed till ignition. The test was repeated at different temperatures till the obtained delay period was exactly $5 \pm 0.1 \mathrm{~s}$.

\section{RESULTS AND DISCUSSION}

\subsection{Results of Thermo chemical calculations for NTO based explosive formulations}

The characteristics of explosive formulations are very important for theory and practice, because they allow evaluation and comparison of explosives and are necessary to determine the explosive composition which gives the required high performance. Besides the composition of products of explosive conversion there are also the specific volumes of products, explosion heat, and explosion temperature, power of explosive and explosive pressure. Knowing the composition of products of explosive conversion we may deal with calculating the other characteristics of explosives. The explosive characteristics of NTO and various formulations of NTOTNT and NTO-PU calculated by using thermodynamic program are shown in table (2) and table (3).

It is obvious that for the formulations containing mixtures of NTO and TNT, explosion heat and temperature decrease as the weight percentage of NTO increase. On the other hand the values of the volume of detonation gaseous products, pressure, explosive force, and detonation velocity increase. This means that the shattering effect of the formulation (NTO/TNT) increases with increased NTO content.

For the formulations based on NTO/PU mixture, it is obvious that all parameters decrease with the weight percentage of PU increase. This means that the shattering effect of the formulation (NTO/PU) decreases with increased PU content.

Theoretical calculations obtained from the computer program showed that increase of NTO\% in both prepared formulations (NTO/TNT) and (NTO/PU) causes an increase in the shattering effect and detonation velocity. We chose NTO/TNT (65/35) 
and NTO/PU (88/12) because of the process of casting; (formulations higher than that percentage is difficult to cast).

Table (2) Explosive characteristics of NTO-TNT explosive formulations

\begin{tabular}{|c|c|c|c|c|c|c|c|c|}
\hline \multicolumn{2}{|l|}{ Name } & $\begin{array}{l}\text { TNT } \\
\text { pure }\end{array}$ & \begin{tabular}{|l|}
$20 \%$ NTO \\
$80 \%$ TNT \\
\end{tabular} & $\begin{array}{l}35 \% \text { NTO } \\
65 \% \text { TNT } \\
\end{array}$ & $\begin{array}{l}50 \% \text { NTO } \\
50 \% \text { TNT } \\
\end{array}$ & $\begin{array}{l}65 \% \text { NTO } \\
35 \% \text { TNT } \\
\end{array}$ & \begin{tabular}{|l|}
$80 \%$ NTO \\
$20 \%$ TNT \\
\end{tabular} & $\begin{array}{l}\text { NTO } \\
\text { pure }\end{array}$ \\
\hline \multirow{4}{*}{$\begin{array}{c}\text { Summary } \\
\text { formula }\end{array}$} & C & 30.819 & 27.731 & 25.415 & 23.10 & 20.78 & 18.468 & 15.38 \\
\hline & H & 22.013 & 20.686 & 19.691 & 18.697 & 17.7 & 16.707 & 15.38 \\
\hline & 0 & 26.416 & 25.748 & 25.247 & 24.747 & 24.62 & 23.745 & 23.077 \\
\hline & $\mathbf{N}$ & 13.208 & 16.720 & 19.355 & 21.984 & 24.24 & 27.258 & 30.77 \\
\hline \multicolumn{2}{|c|}{$\Delta U_{f} \quad(k c a l / k g)$} & -27 & -43.6 & -56 & -68.5 & -80.95 & -93.4 & -110 \\
\hline \multicolumn{2}{|c|}{$\rho \quad\left(\mathrm{g} / \mathrm{cm}^{3}\right)$} & 1.65 & 1.7 & 1.738 & 1.775 & 1.812 & 1.87 & 1.9 \\
\hline \multicolumn{2}{|l|}{ Ob } & -73.97 & -64.09 & -56.7 & -49.3 & -41.3 & -34.5 & -24.6 \\
\hline \multirow{6}{*}{$\begin{array}{l}\text { Gaseous } \\
\text { product }\end{array}$} & $\mathrm{CO}$ & 13.512 & 13.953 & 14.293 & 14.63 & 15.10 & 15.33 & 12.542 \\
\hline & $\mathrm{CO}_{2}$ & 2.957 & 2.7515 & 2.594 & 2.43 & 2.35 & 2.10 & 2.83 \\
\hline & $\mathrm{H}_{2} \mathrm{O}$ & 6.99 & 6.289 & 5.767 & 5.25 & 4.82 & 4.22 & 4.87 \\
\hline & $\mathrm{H}_{2}$ & 4.016 & 4.057 & 4.079 & 4.10 & 4.03 & 4.13 & 2.82 \\
\hline & $\mathbf{N}_{2}$ & 6.604 & 8.36 & 9.678 & 10.99 & 12.12 & 13.63 & 15.325 \\
\hline & C & 14.35 & 11.023 & 8.528 & 6.03 & 3.33 & 1.04 & zero \\
\hline \multicolumn{2}{|c|}{$\sum n \quad$ (moles) } & 34.079 & 35.41 & 36.41 & 37.4 & 38.4 & 39.4 & 38.5 \\
\hline \multicolumn{2}{|c|}{$V_{o}\left(\mathrm{~cm}^{3} / \mathrm{g}\right)$} & 763.37 & 793 & 815.58 & 838 & 861 & 883 & 861 \\
\hline \multicolumn{2}{|c|}{ D $(\mathrm{m} / \mathrm{s})$} & 6913 & 7125 & 7279 & 7425 & 7604 & 7769.9 & 7891 \\
\hline \multicolumn{2}{|c|}{ P (kbar) } & 197.139 & 218 & 230 & 245 & 262 & 282 & 296 \\
\hline \multicolumn{2}{|c|}{ Q (kcal/kg) } & 1014 & 949 & 901 & 853 & 820 & 756 & 771 \\
\hline \multicolumn{2}{|c|}{$F \quad(j / g)$} & 967 & 982 & 992 & 999 & 1020 & 1004 & 1011 \\
\hline \multicolumn{2}{|c|}{$\mathbf{T} \quad(\mathrm{K})$} & 3414 & 3338 & 3277 & 3211 & 3193 & 3064 & 3161 \\
\hline
\end{tabular}


Table (3) Explosive characteristics of NTO-PU, PBXs formulations

\begin{tabular}{|c|c|c|c|c|c|c|}
\hline \multicolumn{2}{|c|}{ Name } & $\begin{array}{c}90 \% \mathrm{NTO} \\
10 \% \mathrm{PU}\end{array}$ & \begin{tabular}{|c|}
$88 \%$ NTO \\
$12 \%$ PU \\
\end{tabular} & $\begin{array}{c}85 \% \text { NTO } \\
15 \% \text { PU }\end{array}$ & $\begin{array}{c}80 \% \text { NTO } \\
20 \% \text { PU }\end{array}$ & $\begin{array}{l}\text { NTO } \\
\text { pure }\end{array}$ \\
\hline \multirow{4}{*}{$\begin{array}{l}\text { Summary } \\
\text { formula }\end{array}$} & C & 20.92 & 22.028 & 23.69 & 26.46 & 15.38 \\
\hline & $\mathbf{H}$ & 24.49 & 26.31 & 29.05 & 33.60 & 15.38 \\
\hline & 0 & 20.99 & 20.57 & 19.94 & 18.89 & 23.077 \\
\hline & $\mathbf{N}$ & 27.75 & 27.15 & 26.24 & 24.74 & 30.77 \\
\hline \multicolumn{2}{|c|}{$\Delta \mathbf{U}_{\mathrm{f}} \quad(\mathrm{kcal} / \mathbf{k g})$} & -112.8 & -113.36 & -114.2 & -115.6 & -110 \\
\hline \multicolumn{2}{|c|}{$\rho \quad\left(\mathrm{g} / \mathrm{cm}^{3}\right)$} & 1.82 & 1.8 & 1.78 & 1.74 & 1.9 \\
\hline \multicolumn{2}{|l|}{ Ob } & -52.95 & -58.625 & -67.144 & -81.328 & -24.6 \\
\hline \multirow{6}{*}{$\begin{array}{l}\text { Gaseous } \\
\text { product }\end{array}$} & $\mathrm{CO}$ & 12.0386 & 11.293 & 10.179 & 8.345 & 12.542 \\
\hline & $\mathrm{CO}_{2}$ & 1.611 & 1.553 & 1.459 & 1.2836 & 2.83 \\
\hline & $\mathrm{H}_{2} \mathrm{O}$ & 5.728 & 6.170 & 6.843 & 7.977 & 4.87 \\
\hline & $\mathrm{H}_{2}$ & 6.561 & 6.984 & 7.682 & 7.682 & 2.82 \\
\hline & $\mathbf{N}_{2}$ & 13.875 & 13.575 & 13.575 & 12.37 & 15.325 \\
\hline & C & 7.27 & 9.181 & 12.052 & 16.831 & zero \\
\hline \multicolumn{2}{|c|}{$\sum \mathrm{n}$ (moles) } & 39.769 & 39.576 & 39.283 & 38.799 & 38.5 \\
\hline \multicolumn{2}{|c|}{$V_{0} \quad\left(\mathrm{~cm}^{3} / \mathrm{g}\right)$} & 890.845 & 886.507 & 879.94 & 869.0957 & 861 \\
\hline \multicolumn{2}{|c|}{ D $\quad(\mathrm{m} / \mathrm{s})$} & 7244.662 & 7115.275 & 6960.959 & 6691.829 & 7891 \\
\hline \multicolumn{2}{|c|}{ P (kbar) } & 238.807 & 227.822 & 215.6245 & 194.795 & 296 \\
\hline \multicolumn{2}{|c|}{ Q (kcal/kg) } & 689.459 & 688.937 & 688.16 & 686.56 & 771 \\
\hline \multicolumn{2}{|l|}{$F \quad(j / g)$} & 860.522 & 837.311 & 804.9164 & 756.53 & 1011 \\
\hline \multicolumn{2}{|l|}{$\mathrm{T} \quad(\mathrm{K})$} & 2602.54 & 2544.759 & 2464.539 & 2345.301 & 3161 \\
\hline
\end{tabular}

\subsection{Melting point}

The melting point was measured for pure NTO and TO and found to be $263.5^{\circ} \mathrm{C}$, and $243{ }^{\circ} \mathrm{C}$ respectively. In the literature [9], the melting point of NTO and TO were found to be very close to the obtained experimental values $\left(264{ }^{\circ} \mathrm{C}\right.$, and $244{ }^{\circ} \mathrm{C}$ respectively) which emphasize the purity of the obtained products. 


\subsection{Infrared spectroscopy}

It is well known that the IR spectra of the organic compounds can be divided into three general regions, the functional region $4000-1300 \mathrm{~cm}^{-1}$. The finger print region $1300-910 \mathrm{~cm}^{-1}$ and the aromatic region from $910-500 \mathrm{~cm}^{-1}$. The results obtained from the IR spectrum of TO and NTO are tabulated in table $(4,5)$ and the obtained absorption spectra for prepared TO and NTO are illustrated in figure (1) and figure (2) respectively

Table (4) IR characteristic absorption of TO

\begin{tabular}{|c|c|c|}
\hline Group & $\begin{array}{c}\text { Wave number } \\
\left.\mathbf{( c m}^{-1}\right)\end{array}$ & $\begin{array}{c}\text { Reference [10] } \\
\left.\text { (cm }^{-1}\right)\end{array}$ \\
\hline $\mathrm{N}-\mathrm{H}$ & 3089.8 & $3300-2500$ \\
\hline $\mathrm{C}-\mathrm{H}$ & 1255.6 & $1300-1000$ \\
\hline $\mathrm{C}=\mathrm{O}$ & 1678 & $1850-1650$ \\
\hline The ring & 1020 & $1040-980$ \\
\hline $\mathrm{C}=\mathrm{N}$ & 1699.2 & $1700-1600$ \\
\hline
\end{tabular}

Table (5) IR characteristic absorption of NTO

\begin{tabular}{|c|c|c|c|}
\hline Group & $\begin{array}{c}\text { Wave number } \\
\left(\mathrm{cm}^{-1}\right)\end{array}$ & $\begin{array}{c}\text { Reference [10] } \\
\left(\mathrm{cm}^{-1}\right)\end{array}$ & NTO[11] \\
\hline $\mathrm{N}-\mathrm{H}$ & 3209.3 & $3300-2500$ & 3211 \\
\hline $\mathrm{NO}_{2}$ & 1546.8 & $1550-1370$ & 1546 \\
\hline $\mathrm{Ring}$ & 1018.3 & $1040-980$ & 1018 \\
\hline $\mathrm{C}=\mathrm{O}$ & 1716.5 & $1850-1650$ & 1719 \\
\hline $\mathrm{C}=\mathrm{N}$ & 1701.1 & $1700-1600$ & - \\
\hline $\mathrm{C}-\mathrm{N}$ & 829.3 & 870 & - \\
\hline
\end{tabular}

It is clear from figures 1 and 2 that the $\mathrm{NO}_{2}$ group which was not present in figure 1 relevant to TO, is found now in figure 2, relevant to NTO, as absorption peak at 1547 $\mathrm{cm}^{-1}$ which emphasizes the nitration step of TO to NTO.

\subsection{Determination of explosive sensitivity to heat}

Sensitivity of the prepared (NTO-TNT 65:35) and (NTO-PU 88:12) explosive formulations to thermal impulses was examined by measuring the ignition temperature and the delay period of ignition at constant temperature (higher than measured ignition temperature). 


\subsubsection{Ignition temperature}

The results of the values of ignition temperature obtained for pure TNT, NTO, NTO/TNT (65:35), (NTO/PU) (88:12) are listed in table (6) with some relevant literature values. From these results obtained it can be seen that the ignition temperature for PBXs based on NTO and PU, seems to be slightly less than that obtained for pure NTO, pure TNT or (NTO-TNT) explosive formulation. The ignition temperature of NTO/TNT $(65: 35)$ explosive formulation $\left(271^{\circ} \mathrm{C}\right)$ was markedly less than that of pure TNT but very close to that of pure NTO. The found literature values for the ignition temperature of pure TNT and pure NTO are very close to those determined experimentally.

Table (6) Ignition temperature for NTO, TNT and (NTO/TNT, NTO/PU) formulations

\begin{tabular}{|c|c|c|}
\hline Property & $\begin{array}{c}\text { Ignition } \\
\text { temperature }\left({ }^{0} \mathrm{C}\right)\end{array}$ & Literature \\
\hline NTO & 274 & $\begin{array}{c}280[1] \\
266[9]\end{array}$ \\
\hline TNT & 300 & $300[12]$ \\
\hline NTO/TNT (65:35) & 271 & - \\
\hline NTO/PU (88:12) & 267 & - \\
\hline
\end{tabular}

It is clear from table(6) that the ignition temperature for formulation (NTO/PU) 88:12 decreased with respect to pure NTO by $3 \%$,which can be attributed to the presence of a thin polymeric coat of the NTO crystals, which act as an energy barrier. It is clear from table (6) that the ignition temperature for formulation (NTO/TNT) 65:35 decreased with respect to pure NTO by $1 \%$.

\subsubsection{Ignition temperature at constant delay periods of ignition}

The values obtained for the ignition temperature at constant delay periods of ignition (5 s) are tabulated in table (7)

Table (7) ignition temperature at constant delay periods of ignition of NTO, TNT, NTO/TNT (65/35), NTO/PU (88/12)

\begin{tabular}{|c|c|c|c|c|}
\hline Property & NTO & TNT & NTO/TNT & NTO/PU \\
\hline $\begin{array}{l}\text { Ignition temperature at constant } \\
\text { delay periods } 5 \mathrm{~s}\left({ }^{0} \mathrm{C}\right)\end{array}$ & 320 & 410 & 380 & 390 \\
\hline
\end{tabular}

It is clear from table(7) that the delay period of ignition for formulation (NTO/PU) $88: 12$ increased with respect to pure NTO by $22 \%$, which can be attributed to the presence of a thin polymeric coat of the NTO crystals, which act as an energy barrier. It is clear from table (7) that the delay period of ignition for formulation (NTO/TNT) $65: 35$ increased with respect to pure NTO by $18 \%$. 


\subsection{Sensitivity to impact}

The results obtained for upper limit of sensitivity to impact energy are listed in table (8).It is clear that formulations based on polyurethane have lower sensitivity to impact than all other formulations based on TNT, or pure TNT and NTO due to the coating of the explosive grains by the polyurethane elastomer. The sensitivity to impact of (NTO -TNT) explosives formulation was markedly decreased when compared with that of pure TNT but higher than that of pure NTO.

Table (8) Sensitivity to impact for pure NTO, pure TNT, NTO/TNT (65/35) and NTO/PU (88/12)

\begin{tabular}{|c|c|c|}
\hline Property & $\begin{array}{c}\text { Impact energy [J] } \\
\text { at } \mathbf{1 0 0} \boldsymbol{\%} \text { initiation }\end{array}$ & Literature \\
\hline NTO & 30 & $22[13]$ \\
\hline TNT & 15 & $15[12]$ \\
\hline NTO/TNT(65:35) & 24 & - \\
\hline NTO/PU(88:12) & 36 & - \\
\hline
\end{tabular}

It is clear from table(8) that with respect to sensitivity of pure NTO to impact the formulation (NTO/PU) $88: 12$ sensitivity to impact was decreased by $20 \%$,this can be attributed to the presence of a thin polymeric coat of the NTO crystals, which act as an energy barrier.

It is clear from table(8) that with respect to sensitivity of pure NTO to impact the formulation (NTO/TNT) 65:35 sensitivity to impact was increased by $20 \%$

\subsection{Sensitivity to friction}

The results are tabulated in table (9); no indication of initiation was noticed even when applying the maximum force $(360 \mathrm{~N})$ of the test apparatus. Similar results were reported [14]. This high resistance to friction enables us to use these formulations in difficult (severe) conditions during production and handling.

Table (9) Sensitivity to friction for pure NTO, pure TNT, NTO/TNT (65/35) and NTO/PU (88/12)

\begin{tabular}{|c|c|c|}
\hline Property & Friction force [N] & Literature \\
\hline NTO & $>360$ & $>353[1]$ \\
\hline TNT & $>360$ & $>353[1]$ \\
\hline NTO/TNT(65:35) & $>360$ & - \\
\hline NTO/PU(88:12) & $>360$ & - \\
\hline
\end{tabular}

It is clear from table (9) that the upper friction sensitivity limit could not be determined, and the formulation (NTO/PU) and (NTO/TNT) proved to be low sensitive to friction. 


\section{CONCLUSIONS}

The experimental work showed that the NTO was successfully prepared in laboratory via the reaction of semicarbazide hydrochloride with formic acid to produce TO followed by its nitration with fuming nitric acid at $25{ }^{\circ} \mathrm{C}$ for 120 minutes with about $65 \%$ conversion. Theoretical calculations obtained from the computer program showed that increase of NTO\% in both prepared formulations (NTO/TNT) and (NTO/PU) causes an increase in the shattering effect and detonation velocity.

Sensitivity to impact was determined and it was found that formulations based on NTO/PU have lowest sensitivity to impact (36 joule) when compared with pure NTO, TNT, and NTO/TNT. Sensitivity to friction showed that no initiation was noticed even when applying the maximum force $(360 \mathrm{~N})$. The ignition temperature of NTO/TNT (65:35) explosive formulation was $271^{\circ} \mathrm{C}$ and for (NTO/PU) (88:12) explosive formulation was $267^{\circ} \mathrm{C}$.

\section{REFERENCES}

[1] Matthew W. Smith and Matthew D. Cliff; " NTO-Based Explosive Formulations: A Technology Review ", Weapons Systems Division, DSTO Aeronautical and Maritime Research Laboratory, Salisbury, South Australia, 1999.

[2] Mohamed Gaber Zaki "Advanced Plastic Bonded Explosives ", M.Sc, thesis, MTC, Cairo, Egypt, 2005.

[3] Jamal Quazzani; "Preventive approach for managing and removing organic pollutants: the example of NTO ", ibid, $31^{\text {st }}, 2000$

[4] Muy L.Chan and Alan D. Turner; "Preparation of fine particulate CL 20 ", US Patent 005712511, 1998

[5] Stanislaw Cudzilo and Waldemar Andrzej Trzcinski; "A study on detonation characteristics of pressed NTO ", international annual conference of ICT, Karlsruhe, Germany, 32 ${ }^{\text {nd }}$, 2001.

[6] Beat Vogelsanger and Beat Berger; " energetic materials - performance and safety", 36 ${ }^{\text {th }}$ International Conference of ICT, Karlsruhe, Germany, , 2005.

[7] Gurdip Singh and Prem S. Felix; "Studies on energetic compounds. An overview of preparation, themolysis and applications of the salts of NTO ", Journal of hazardous materials, 2002.

[8] Suceska M.; "test Methods for Explosives ", Springer-Verlage, 1995.

[9] Tamer Zakaria Wafy "Synthesis and Characterization of some energetic materials for composite rocket propellants ", M.Sc. thesis, MTC, Cairo, Egypt, 2003.

[10] Robert T.- Morrison, Robert N. Boyd "Organic Chemistry" fifth edition, USA, 1987

[11] Zhang Tonglai, Hu Rongzu, Liang Yaniun and Li Fuping; "Preparation and mechanism of thermal decomposition of alkali metal ( $\mathrm{Li}, \mathrm{Na}$ and $\mathrm{K}$ ) salts of NTO ", J. thermal Analysis, 827-847, 39, 1993.

[12] Josef Kohler, and Rudolf Meyer; "explosives", fourth, revised and extended edition, Federal Republic of Germany, 1993.

[13] Alain Becuwe and A,Delclos;Zhang ;" Low-sensitivity explosive compounds for low vulnerability warhead", J.Propellants,Explosive,Pyrotechnics.1-10,18,1993.

[14] Matthew D. Cliff and Matthew W. Smith; "Assessment of a Melt-Castable NTO/TNT Formulation ", DSTO Aeronautical and Maritime Research Laboratory, July 2000. 


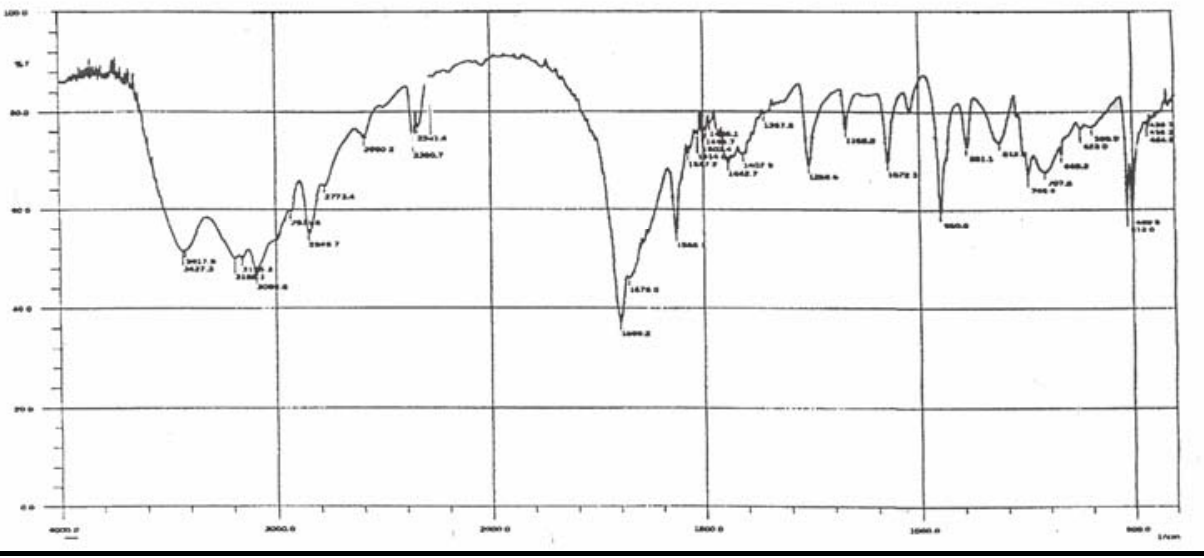

Fig (1) FTIR spectrum of prepared TO

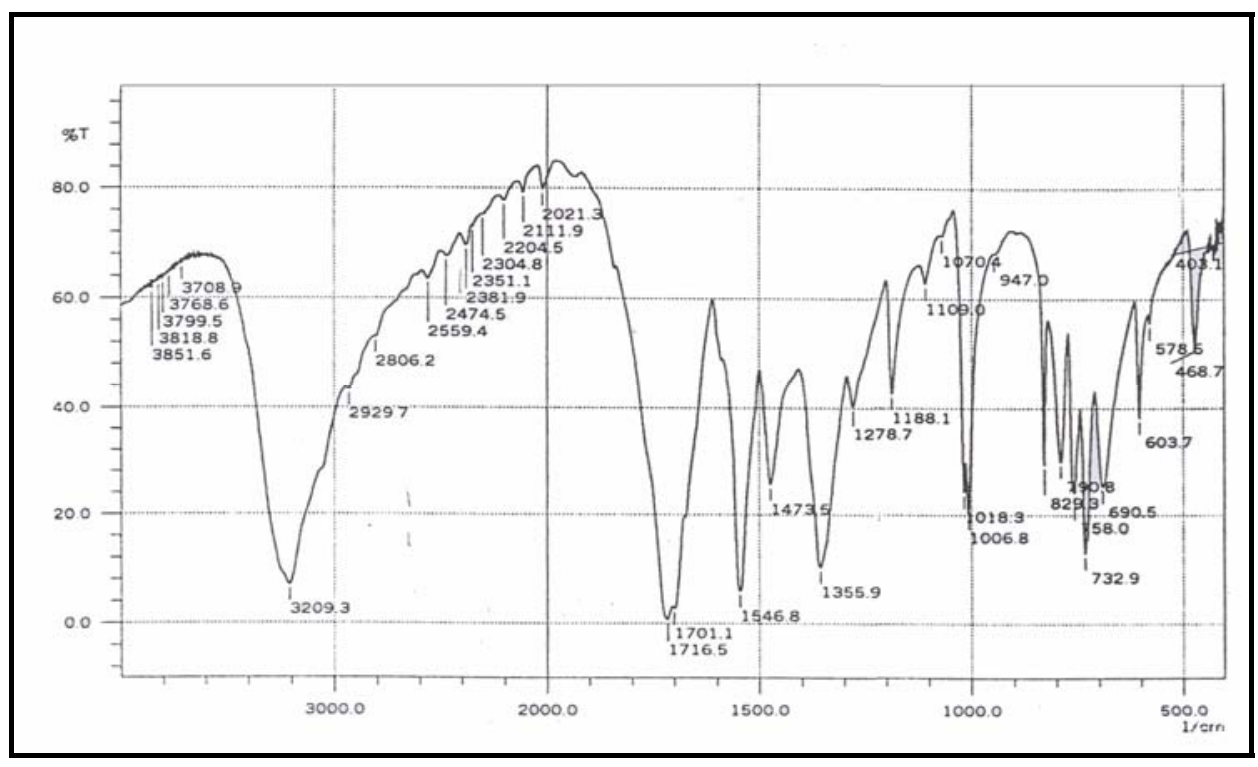

Fig (2) FTIR spectrum of prepared NTO 